\title{
Editorial: On Horace's Odes and Being a Referee
}

As I write this, it has been a few weeks since I had one of those experiences that rarely happens during one's academic career. I was asked to be the external examiner for a Master's thesis in the Classics Department at my university. Like most of you, I consider myself a fairly educated person, but I thought, "What on earth do I really know about the classics and why would they ask someone whose research is on the geography of aging, access to formal and informal care, and the role of volunteers to examine such a thesis?" The thesis, by Aara Macauley, was entitled, "Old Age, Ageing and Death in Horace's Odes". Her supervisor told me that he often tried to choose people from outside the humanities to examine his students' theses. I can report that thesis was an outstanding piece of scholarship and a delight to read, but it also made me think of the challenges of being editor-in-chief of the Canadian Journal on Aging (CJA).

The two greatest challenges I did not realize I would face when I accepted the position are in some ways the same challenges I faced in reading Aara's thesis. While reading the thesis, I kept asking myself what questions I could ask about this piece of scholarship. In much the same way, each time a manuscript arrives in my office, as I read through it, I have to ask myself, "Is the manuscript of sufficient quality to send to a section editor to ask to have the paper reviewed, and if so, to which section editor should I send the paper?" Even though I am no expert on Horace's Odes, I did find sufficient parallels between his descriptions of aging and the attitudes towards seniors in Octavian Rome to come up with questions based on my contemporary understanding of these issues. Similarly, even though I am not an expert on every aspect of gerontology, I am pleased to report that rarely do I decide that there is insufficient merit to send a manuscript to a section editor, and most of the time the section editors do not question why I have sent a manuscript to them.

The second challenge all thesis examiners ultimately have is to decide the outcome of the written work and the oral defence. In Aara's case, this was easy. The thesis was an outstanding piece of scholarship. As editor-in-chief, I ultimately have to decide the fate of each manuscript, based on the hard work of reviewers and section editors. Section editors make recommendations, which, when negative, I know are not easy to make, and I, in turn, have to communicate the results to the author. In many ways, the referees, the section editors, and I are like a thesis committee. Even when I reject a manuscript, I hope the author will learn from the reports we send, rework the manuscript, and find the appropriate venue for the research, even if that is not the CJA.

If I had to grade my own work as your editor-in-chief over the past two years, I would likely give myself a grade in the " $\mathrm{B}$ " range. I am proud of some of the experiments we have tried in publishing papers and editorials a little outside of the norm, of the changes we have made to the structure of the editorial board, and of our playing a role in the Congrès international francophone de gérontologie et gériatrie by publishing their abstracts as a supplement to the journal. Moving to electronic submission has not progressed as quickly as I had wanted, and perhaps most frustrating to me and I am sure to more than a few would-be authors, has been the time it sometimes takes to get a first set of referees' reports. I have no easy solutions for this problem, because the problem is increasingly the difficulty we have in getting qualified researchers to agree to act as referees and to submit their reports in a timely way.

This brings me back to Aara's thesis. Even though it would have been easy for me to decline the invitation to examine the thesis because of my uncertainty that I was the best person to be the external examiner and because of the many other duties I have at my university, I agreed. I learned a lot. I found a few editorial problems with the thesis, and I had some questions I wanted Aara to answer. I hope next time you are asked to referee a paper for the $C J A$, even when you are uncertain about whether you are the best person or you have many other pressing duties, you will say "yes" and, like me, realize that, through our participation in all aspects of the research process, we are continually learning, contributing to the CJA and to the development of gerontology as a discipline.

As always, please contact me at rosenber@post. queensu.ca if you have any thoughts about this editorial or any other aspect of the CJA.

Mark Rosenberg

Editor-in-Chief 